\title{
Inventory of Pediatric Neurology "Manpower" in Canada
}

\author{
Daniel L. Keene, Peter Humphreys
}

\begin{abstract}
Objective: To review the demographics and workload characteristics of pediatric neurology in Canada. Method: A standardized survey questionnaire was mailed out to practicing pediatric neurologists in Canada in 2001. Variables examined were age, gender, hours on call, regular hours worked per week, type of practice and projected changes in practice over next five to ten years. Results were compared to the 1994 Pediatric Neurology Manpower Survey which had used the same survey instrument. Results: Fifty-six (70\%) pediatric neurologists practicing in Canada returned the survey. As was the case in 1994, no significant differences in workload were found based on age or gender. The average age of the practicing pediatric neurologist in 2001 was 51 years compared to 45 years in 1994. The proportion of physicians over 55 years in 2001 was $35 \%$ compared to $25 \%$ in 1994. Conclusions: Pediatric neurology in Canada is an aging specialty needing a significant recruitment of new members.
\end{abstract}

RÉSUMÉ: Inventaire de la « main d'œuvre » en neurologie pédiatrique au Canada. But: Revoir les caractéristiques de la démographie et de la charge de travail en neurologie pédiatrique au Canada. Méthode: L'étude a été effectuée au moyen d'un questionnaire standardisé posté aux neurologues pédiatriques en pratique active au Canada en 2001. On a examiné les variables suivantes: l'âge, le genre, le nombre d'heures de garde, le nombre d'heures de travail régulier par semaine, le type de pratique et les changements projetés dans la pratique dans les 5 à 10 prochaines années. Les résultats ont été comparés à ceux de l'étude sur la main d'œuvre en neurologie pédiatrique réalisée en 1994 au moyen du même instrument. Résultats: 56 (70\%) des neurologues pédiatriques en pratique active au Canada ont retourné le questionnaire. Comme on l'avait constaté en 1994, aucune différence significative dans la charge de travail n'a été notée selon l'âge ou le genre. L'âge moyen de ces neurologues était de 51 ans en 2001 comparé à 45 ans en 1994 et 35\% d'entre eux avaient plus de 55 ans en 2001, comparé à $25 \%$ en 1994. Conclusion: Le recrutement de nouveaux spécialistes en neurologie pédiatrique s'impose à cause du vieillissement de la main d'œuvre dans ce domaine au Canada.

Can. J. Neurol. Sci. 2005; 32: 306-310

Controlling government budget deficits has been a prime objective of all levels of government ${ }^{1}$. This has been done mainly by "cuts to services" or "holding the line" in expenditures rather than by increasing government revenues. As health care in Canada accounts for a significant percentage of government expenditures, it became a prime target of budget control exercises. ${ }^{1}$ Corresponding changes in health care policy at the various levels of government have occurred. As governments viewed physician-generated services as the principal reason for the rapidly increasing costs of health care, this was a key focus point of the cost controlling exercise. ${ }^{2}$ The primary causes of expenditure excess in health were felt to be excessive physician numbers, inappropriate distribution of physicians, inappropriate use of health care facilities and lack of use of alternate, less expensive methods of providing some types of health care services. ${ }^{3}$ The number of entry-level places for students in medical schools was reduced. Postgraduate positions were reduced for some of the specialties. The option of alternate "envelope" funding of physicians rather than the "fee for service" method was developed. ${ }^{3}$ Restructuring of hospital

From Department of Pediatrics, Division of Pediatric Neurology, Children's Hospital of Eastern Ontario, Ottawa, Ontario, Canada

ReCEIVED January 7, 2005. ACCEPTED IN Final FORM MARCH 29, 2005.

Reprint requests to: Daniel L. Keene, Department of Pediatrics, Division of Pediatric Neurology, Children's Hospital of Eastern Ontario, Ottawa, ON K1H 8L1 Canada 
systems with hospital mergers or closures occurred.

Government estimates of physician specialist manpower, however, may have been based on erroneous assumptions. For pediatric neurology, this is particularly the case. Pediatric neurology is not a stand alone specialty as defined by the Royal College of Physicians and Surgeons of Canada, (RCPSC) but rather has evolved as a subspecialty of neurology. Having obtaining a specialist certification in pediatrics prior to entry into and completion of a RCPSC-mandated training program in pediatric, a number of individuals currently practicing child neurology, have elected not to sit for the specialty examination in neurology. As a result, there are a number of practicing pediatric neurologists who are certified in pediatrics but not neurology. To further complicate the issues, governments (for billing purposes) have chosen not to recognize pediatric subspecialties to the same extent as adult subspecialties. As a result, when governments use physician billing numbers to estimate the number of practicing physicians in a specialty, pediatric neurologists are often classified as either general pediatricians or neurologists. These two factors can lead to an underestimation of pediatric neurology manpower and an overestimation of general pediatric/neurology manpower. A falsely low estimate of the number of practicing pediatric neurologists would result in a significant underestimation of the numbers of such specialists required to maintain current levels of specialized care in the future.

The Canadian Association for Child Neurology (CACN) decided to repeat the "manpower needs survey" originally performed in 1994. This paper reports the comparison between the two survey results.

\section{METHOD}

To allow for comparison of trends, the same standardized questionnaire that had been previously used in the 1994 survey was employed for the present survey. ${ }^{4}$ The original questionnaire detailing demographics, education, practice and productivity indices was based on the model of Rieder et al. ${ }^{5}$ The questionnaire was mailed to all practicing members of the $\mathrm{CACN}$ in 2001. Non-responders were contacted by telephone

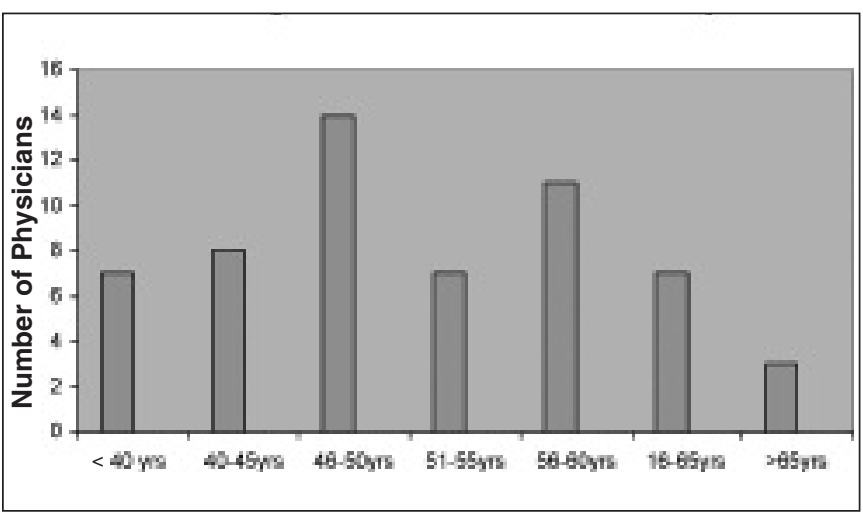

Figure 1: Distribution of the ages of practicing pediatric neurologists in Canada at time of the survey one month after initial mailing to remind them to complete the survey forms. To check for accuracy of ascertainment, Canadian university program directors in child neurology were contacted by phone and asked about numbers of physicians practicing child neurology in their region, as well as their personal projection of regional manpower needs for the next five years. In cases where physicians were identified by the program directors as practicing in the region but not listed with the $\mathrm{CACN}$, these people were contacted and asked to complete the same questionnaire as was completed by the members of the Association.

The data were analyzed using SSPS $10 .^{6}$ The data were analyzed for gender, age, and years of practice. Chi squared analysis was used for the analysis of proportional data. Continuous variables were analyzed with the use of analysis of variance. Significance was established at p value less than 0.05 .

\section{RESULTS}

Eighty practicing child neurologists in Canada received the questionnaire of which $56(70 \%)$ returned a completed survey. Based upon information from this survey, the mean age of the practicing pediatric neurologist in Canada was $51 \pm 10$ years of age at the time of this survey (age range 33 to 80 years) (see

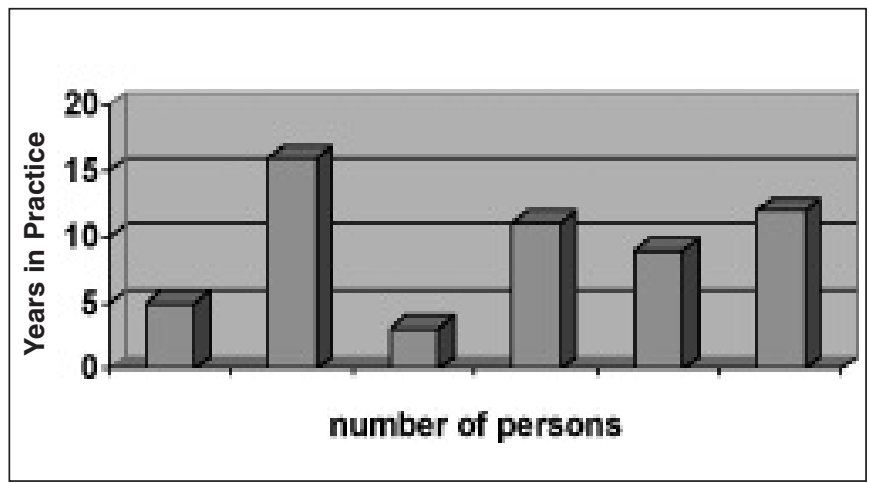

Figure 2: Distribution of years practicing pediatric neurology

Figure 1). Thirty-six percent of the group was greater than 54 years of age. The mean age of practicing male pediatric neurologists was $54 \pm 10$ years compared to $46 \pm 7$ years for female pediatric neurologists. Sixteen $(28 \%)$ of the pediatric neurologists had obtained specialty certification from the Royal College of Physicians and Surgeons of Canada in pediatrics only, $22(40 \%)$ in neurology only and $18(32 \%)$ had specialty certification in both pediatrics and neurology.

The average length of time in active practice for the group as a whole was $17 \pm 10$ years with $38 \%$ having been in practice longer than 20 years and $23 \%$ being less than 10 years in practice (see Figure 2). Males had been in practice on average $20 \pm 10$ years, while the mean length of time for females was $12 \pm 8$ 


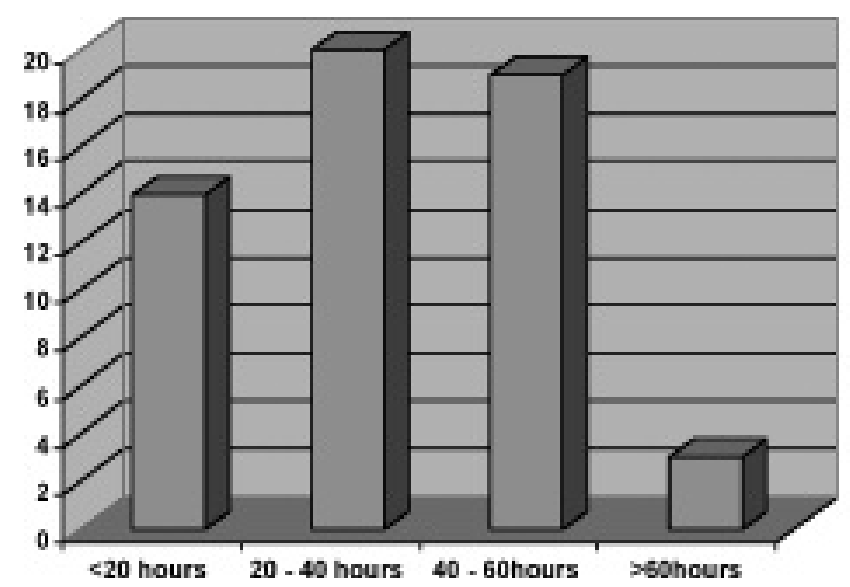

Figure 3: Number of hours worked per Enariber af perions week excluding call hours

years. The ratio of male to female physicians was 3:1.

The average number of non-call hours per week worked by each member was $38 \pm 18$ (see Figure 3). The mean number of additional hours spent on call each month was 162 . No significant differences for hours worked were seen when data were analyzed for gender, age or duration of practice. On average clinical care of patients took up $62 \%$ of the responders' total time, while $13 \%$ was spent in research, $8 \%$ in teaching and $3 \%$ in administration.

The ratio of pediatric neurologist to population of children varied over the country (see Figure 4).

The mean outpatient clinical workload per neurologist was nine new patient consultations per week and 18 patients seen in follow-up. The average inpatient load per pediatric neurologist

\begin{tabular}{cc}
\hline $\begin{array}{c}\text { Figure 4: Ratio of pediatric neurologist per million children } \\
\text { Geographic area }\end{array}$ & Ratio* \\
\hline Canada & 9.59 \\
Quebec & 6.89 \\
Ontario & 10.51 \\
Manitoba & 12.59 \\
Saskatchewan & 9.28 \\
Alberta & 7.98 \\
British Columbia & 9.66 \\
New Brunswick & 7.46 \\
Newfoundland & 11.08 \\
Novia Scotia/PEI & 6.88
\end{tabular}

* pediatric neurologist per million children. was five consultations per week. Forty-nine (87.5\%) responders indicated that they were involved in multi-discipline specialty clinics dedicated to a specific pediatric neurological disorder (e.g. epilepsy, neuromuscular, neuro-oncology, etc).

All responding pediatric neurologists had active hospital privileges. Fifty $(89.3 \%)$ of the responding physicians had full time university and/or teaching hospital appointments.

Physician remuneration was variable. Fifty-five percent reported that their main source of payment was from provincial ministry "fee for service" plans. Nineteen percent stated that they were part of an alternate payment plan. Less than 5\% received their monies from hospital sources or research funding. As for university salaries, $17 \%$ reported that this occurred to some degree, but was not the main source.

When respondents were asked to predict length of time before retiring from active clinical practice, $11(20 \%)$ stated that they plan to do so within the next five years. Another 11 (20\%) reported planning to retire within the next ten years.

When respondents were asked if there were sufficient numbers of practicing pediatric neurologists in their areas to meet the clinical needs of the patient population, 52 (92.9\%) responded that there were not.

Program directors reported that in 2001 there were five training programs in pediatric neurology capable of accepting new trainees at rates varying from one person per year to one every three years. In two programs funding was guaranteed while in the other their funding was on a competitive basis with other subspecialties. It was estimated that the Canadian training programs, at the time of the survey, had the capacity to generate two to three new pediatric neurologists per year. Based on estimated losses through attrition between 1994 and 2000, plus existing vacant positions, the estimated number of trainees needed to maintain the status quo would be a minimum of three new pediatric neurologists per year.

\section{DisCUSSION}

The results of the present survey are similar to those of the 1994 survey. $^{4}$

Both surveys showed a wide variation in individual practice patterns. The overall percentages of time individual pediatric neurologists devoted to clinical practice, teaching, research and administration remained the same. A trend to development of subspecialty clinics was seen between survey periods. In 1994, it was uncommon for a pediatric neurologist to be involved in a multi-discipline disease- specific clinic; whereas, in the present survey, over $89 \%$ of responders reported such involvement. Both surveys did not report significant differences in workload based on age or gender.

A worrisome trend was noted regarding the average age of the Canadian pediatric neurologist: the "typical" pediatric neurologist was getting older! In the 1994 survey, the mean age was 45 years; whereas in the present survey it was 51 years. As well, the proportion of practicing physicians over 55 years of age has increased between surveys (25\% in 1994 compared to 35\% in 2002).

Both of our "manpower" surveys employed the usual method for determining manpower needs for a medical specialty which 
is to survey physicians in practice at a set period in time. A ratio of specialists to population is then calculated and compared to a previously agreed-upon standard ratio for that medical specialty. The number of new physicians needed is then determined by having the actual ratio approach the "desired" ratio, while taking into account the attrition of physicians from practice over a set period of time.

The assumption that the ratio of the "desired number" of physicians to population adequately reflects manpower needs may not be accurate. The "desired number of physicians" is often obtained through consensus discussions by panels of experts. The ratios used are often broad and general in scope and do not reflect the needs of specific medical subspecialties. These ratios make a statement about the specialty practice environment at one point in time and are not responsive to ongoing changes in needs of either patients or physicians. Changes in population demographics, physician practice styles, medical technology, patients' demands for specialized services and referral patterns ${ }^{3}$ are not reflected in these static ratios. Without a clear description of the relationships between the various components of physician work patterns, desired life style, and the demand for physician services by the population, adequate predictions of future needs cannot be made. Changes in any one of these components can result in a dramatic change in the projected numbers of physicians needed to meet the needs of the population under study.

The breakdown of workload of physicians by gender and age may reveal life style trends to be assessed. In both our surveys, significant effects of age or gender on work patterns were not found. This differed from the findings of Reider et $\mathrm{al}^{8}$ for general pediatricians. They reported significant differences in the number of hours spent in clinical practice and the number of patients seen by individual physicians. Women pediatricians and younger physicians tended to work fewer hours and see fewer patients in comparison to an older male grouping of physicians.

Although younger pediatric neurologists were not found to have different practice patterns from their older colleagues in 2001, this situation is likely to change in the future. There are several reason for this assertion. First, most provincial regulating bodies require that physicians should arrange for 24 hour coverage of their medical practices in order to maintain an appropriate level of standard of care. This dictates that physicians within a specialty work together for call purposes. Given projected changes in physician life styles and patient safety concerns, the number of hours that a single physician is willing to be "on call" is expected to decrease. This decrease will necessitate an increase in the number of pediatric neurologists required to meet the provincial regulators' request for 24 hour coverage. Projections of numbers of physicians necessary to provide service in a certain region by use of standardized physician-population ratios do not take this need into consideration. Consequently, insufficient physician manpower coverage for a particular area may develop overtime.

Second, changes in the work load mix of physicians (e.g. percentage time spent in clinical practice, research, administration and teaching) is not reflected in static ratios. This becomes particularly important in medical specialties consisting of small numbers of practicing physicians with heavy academic commitments, such as pediatric neurology. As universities place greater emphasis on excellence in research and teaching activities for promotion through the ranks, the clinical activities of academic physicians will necessarily decrease. At the same time, patient demands and expectations for high quality clinical service will continue. Thus, any decrease in the percentage of time an individual physician is not available for clinically-related work will translate into the need for additional physicians if the same level and quality of clinical service are to be maintained.

Third, medical technology is changing rapidly. Computerized tomography, magnetic resonance imaging and magnetic resonance angiography have for the most part replaced older invasive diagnostic procedures such as myelography, pneumoencephalography and cerebral angiography. These newer procedures have allowed for more accurate localization and diagnosis. As a result, surgical intervention has become more aggressive. New drug therapies now offer the hope of better control of some pediatric neurological disorders such as epilepsy. Chemotherapy and radiotherapy protocols for the treatment of neoplasms of the nervous system in children have resulted in greater numbers of long term survivors than in the past. Improved neonatal care has allowed the survival of premature infants who in the past would have died. These changes have resulted in an increased demand for child neurologists not only in the early diagnostic and treatment phase of these disorders but in the ongoing long term evaluation and management of the increasing number of patient survivors with chronic central nervous system disorders. To meet this need, multi-discipline subspecialty clinics involving pediatric neurologists have developed. This is reflected in a marked increase in the reported numbers of physicians involved in neurologically related specific multi-discipline clinics. It also implies the need for determining not only the number of pediatric neurologists needed, but also an assessment of the numbers of other health professionals and technologists required to meet the long term needs of children with neurological disorders.

Both the demand and supply sides of the equation (i.e. physicians to population ratios) need to be examined. Variability of population demographics and physician expertise across the country need to be identified when developing a national or provincial physician "manpower" plan, especially as multidiscipline subspecialty teams develop. Careful assessment of regional needs and a decision as to who will provide what services will be required. Physicians through their national societies will need to develop ongoing action plans based on accurate data if they wish to remain key stake holders in health care.

In summary the average age of the practicing pediatric neurologist in Canada increased between 1994 and 2001. Given the annual average number of trainees produced by the Royal College approved training programs in 2001, the programs would be expected to have difficulty replacing losses through attrition, let alone cope with demands for new services. When using static physician ratios in planning future physician manpower needs, caution must be taken to avoid mistakes that have resulted in the present impoverished state of physician manpower. The comparison of the two CACN surveys shows the benefit of a national society doing periodic physician manpower surveys within their specialty. 


\section{REFERENCES}

1. Laxar H, St-Hilaie F. Money. Politics and Health Care, The Institute for Research on Public Policy and the Institute of Intergovernmental Relations, 2004

2. Evans RG, Barer M, Hertzman G. The 20 year experiment accounting for, explaining and evaluating health care cost containment in Canada and United States Annu Rev Public Health 1991; 12: 481-518.

3. Barer M, Stoddart G. Toward Integrated Medical Resource Policies for Canada - a report prepared for federal/ provincial/territorial conference of deputy ministers of Health, June 1999; 1.1-1.12.
4. Keene D, Humphreys P. "Pediatric neurology manpower requirements" Annals RCPCSC 1997; 30: 165-168.

5. Rieder M, Hanmer S, Haslam R. Pediatric Manpower in Canada: a cross-country survey. CMAJ 1983; 140: 145-150.

6. SPSS PC Version 10, SPSS Inc. Chicago, Illinois

7. Maclean W, Huras P, Burn S. Medical Manpower Planning. Forum 1990; 28 - 33.

8. Rieder M, Hanmer S, Haslam R. Age and Gender - Related Differences in clinical productivity among Canadian Pediatricians. Pediatrics 1990; 90: 144-149. 